\title{
Enterprise Architecture Planning Sistem Informasi Akademik Dengan TOGAF ADM
}

\author{
Azhar Basir' ${ }^{1}$, Abdul Fadlil'2, Imam Riadi ${ }^{3}$ \\ ${ }_{1}^{1}$ Program Studi Teknik Informatika, Universitas Ahmad Dahlan \\ 2Program Studi Teknik Elektro, Universitas Ahmad Dahlan \\ ${ }^{3}$ Program Studi Sistem Informasi, Universitas Ahmad Dahlan \\ Jl. Prof. Dr. Soepomo, Umbulharjo, Janturan Yogyakarta 55164 \\ 1azharbasir28@gmail.com, 22 fadlil@mti.uad.ac.id ,3imam.riadi@is.uad.ac.id
}

\begin{abstract}
The role of information technology greatly influences the improvement of a higher education governance, so that universities today should have models and standards that can be implemented as a reference in enhancing harmony between business strategies and information technology. Enterprise Architecture planning (EAP) is one of the methodologies that can be applied in planning information architecture, the stages in EAP consist of data architecture, application architecture, technology architecture and how the design that has been made can be implemented to support business activities, to achieve the organization's mission.
\end{abstract}

Keywords: Enterprise, Architecture, Planning, System, Information

\begin{abstract}
Abstrak
Peranan teknologi informasi sangat mempengaruhi peningkatan tata kelola perguruan tinggi, sehingga perguruan tinggi saat ini haruslah memiliki model dan standar yang dapat diimplementasikan sebagai acuan dalam meningkatkan keselarasan antara strategi bisnis dan teknologi informasi. Enterprise Architecture planning (EAP) merupakan salah satu metedologi yang bisa diterapkan dalam membuat perencanaan arsitekture informasi, tahapan-tahapan dalam EAP terdiri dari arsitektur data, arsitektur aplikasi, dan arsitektur teknologi serta bagaimana rancangan yang sudah dibuat dapat diimplementasikan agar dapat mendukung aktifitas bisnis sehingga dapat membantu dalam mencapai misi organisasi..
\end{abstract}

Kata kunci: Enterprise, Architecture, Planning, sistem, informasi

\section{PENDAHULUAN}

Data dan informasi yang ada diperguruan tinggi sangat kompleks, sehingga perlu adanya pengelolaan yang baik dan benar[1]. Pembangunan sistem informasi merupakan salah satu usaha dalam mengelola data dan informasi, agar nantinya data dan informasi dapat di gunakan dan dimanfaatkan oleh masing-masing unit bisnis diperguruan tinggi, untuk membangun sistem informasi diperlukan adanya perencanaan agar nantinya sistem informasi yang dibangun tidak tumpang tindih serta bisa terintegrasi antar sistem informasi diunit satu dengan unit yang lainya, sehingga perputaran data dan informasi yang dibutuhkan dimasing-masing unit bisnis dapat terpenuhi[2]. Sekolah tinggi manajemen informatika dan komputer Muhammadiyah Paguyangan Brebes (STMIKMPB) didirikan pada tanggal 27 sya'ban 1435 H, bertepatan tanggal 25 juni 2014 M. Peningkatnya jumlah mahasiswa setiap tahunnya mengharuskan manajemen untuk terus 
berbenah dalam pengelolaan data dan pelayanan terhadap mahasiswa serta masyarakat, pembangunan sistem informasi merupakan langkah yang dilakukan manajemen saat ini, untuk membangun sistem informasi perlu adanya perencanaan yang matang agar perputaran informasi di masingmasing unit dapat terpenuhi dan tidak hanya perorientasi pada kebutuhan saat ini tetapi juga pada kebutuhan yang akan datang[3], untuk mendapatkan perancangan sistem informasi yang baik harus dilihat berbagai sudut pengembangan sistem informasi dimulai dengan mendefinisikan arsitektur bisnis organisasi, mendefinisikan arsitektur data untuk mengetahui data apa saja yang digunakan dimasing-masing unit organisasi, mendefinisikan arsitektur aplikasi untuk mengetahui aplikasi apa saja yang di butuhkan organisasi, mendefinisikan arsitektur teknologi untuk mengetahui teknologi apa saja yang dibutuhkan untuk mendukung sistem informasi tersebut[4]. Sistem informasi akademik adalah sistem yang dirancang untuk memenuhi kebutuhan perguruan tinggi dalam mengelola kegiatan akademik secara terstruktur sehingga mempermudah pengelolaan data akademik dan mempercepat pelayanan akademik[5]. Sebagai perguruan tinggi baru STMIKMPB belum memiliki sistem informasi akademik, proses-proses yang berhubungan dengan akademik masih dilakukan secara manual sehingga pelayanan membutuhkan waktu yang lama dan pengelolaan data akademik tidak tertata dengan baik.

Enterprise architecture planning (EAP) merupakan metode yang dapat mewujudkan gambaran tentang organisasi secara logis dan lengkap, dengan Adanya Enterprise Architecture (EA) akan memberikan gambaran kondisi saat ini dan kondisi yang diharapkan sehingga akan tercipta keselarasan antara strategi bisnis dan teknologi informasi[6]. Kerangka kerja TOGAF ADM digunakan dalam penelitian ini, dimana kerjangka kerja Framework ini menyediakan pendekatan yang luas dan lengkap untuk mendesian, merancang, mengimplementasi dan melakukan kontrol dengan otoritas pada informasi architecture interprise[7]. Pada penelitian yang dilakukan oleh melda agarina tentang pemanfaatan framework TOGAF untuk perencanaan sistem informasi manajemen aset dan logistik yang menghasilkan kebutuhan arsitektur aplikasi untuk masing-masing unit kerja, serta panduan pengelolaan SI di biro managemen aset dan logistik[8].

penelitian mengenai analisis tatakelola teknologi informasi menggunakan framework COBIT 5 pada domain delivery, Service, and Suport (DSS) yang dilakukan oleh Imam Riadi dkk, yang menghasilkan sebuah analisis tatakelola teknologi informasi pada domain delivery, Service, and Suport (DSS)[9]. Kemudian Penelitian yang dilakukan oleh Roni Yunis dan kridanto Surendro tentang implementasi Enterprise Architecture Perguruan Tinggi, yang menghasilkan tatacara bagaimana sebuah perguruan tinggi mengimplementasikan Enterprise Architecture (EA) untuk meningkatkan tatakelola perguruan tinggi dan menyelaraskan strategi bisnis dengan menerapkan TI dalam perguruan tinggi, serta menjelaskan beberapa tantangan terbesar bagi perguruan tinggi dalam mengimplementasikan 
kebutuhan EA dan bagaimana cara mengatasinya[10]. Berdasarkan penelitian-penelitian terdahulu, maka penulis bermaksud untuk meneliti dan membuat sebuah konseptual Architecture Enterprise yang mencakup arsitektur data, arsitektur aplikasi, dan arsitektur teknologi untuk pengembangan sistem informasi akademik STMIKMPB dengan menggunakan metodologi Enterprise Architectur Planning (EAP) dan menerapkan kerangka kerja the open group architecture Framework (TOGAF).

\section{METODOLOGI PENELITIAN}

Pada penelitian ini beberapa metode berupa alur kerja digunakan untuk menyelesaikan masalah-masalah :

a. Perumusan masalah : permasalahan-permasalahan yang ditemukan dikumpulkan dan disatukan dalam suatu research quistion kemudian research quistion inilah yang nantinya digunakan sebagai pedoman untuk menentukan arah fokus pada penelitian ini

b. Studi literatur : mencari literatur yang terkait dengan penelitian yaitu berupa buku teks dan jurnal ilmiah dan lainya yang nantinya bisa digunakan sebagai review, pembanding dari masing-masing penelitian

c. Pengumpulan data :pengumpulan data dilakukan secara kualitatif dengan yaitu dengan melakukan observasi, wawancara dan analisis dokumen yang terkait dengan penelitian.

d. Analisis dan perancangan : metode analisis yang digunakan dalam penelitian ini adalah metode deskriptif, karena penelitian ini bertujuan untuk mendiskripsikan alur proses akademik yang ada di STMIK Muhammadiyah Paguyangan, sehingga dapat direkomendasikan perbaikannya. Hasil analisis yang didapat digunakan sebagai panduan dalam membuat rancangan Blueprint yang akan dibangun, hasil dari tahap ini berupa rancangan arsitektur data, arsitektur, arsitektur aplikasi dan arsitektur teknologi.

e. Melakukan verifikasi dan validasi terhadap blueprint yang akan di usulkan

f. Kesimpulan dan saran : berisi kesimpulan dan saran yang diperoleh dari hasil penelitian yang telah dilakukan.

\subsection{Metode pengumpulan data}

Pada penelitian ini pengumpulan data menggunakan dua metode yaitu :

a. Observasi : metode ini dilakukan dengan berkunjung langsung ke objek penelitian untuk mendapatkan data-data yang dibutuhkan yang berhubungan dengan kondisi sistem akademik saat ini dengan melakukan pengamatan secara langsung dan pencatatan dokumen.

b. Wawancara : wawancara dilakukan dengan pihak-pihak terkait dengan bagian akademik serta dengan pimpinan STMIK Muhammadiyah Paguyangan, metode ini dilakukan untuk memastikan data-data yang diperoleh telah sesuai dengan fakta, wawancara sangat efektif untuk 
mengetahui strategi dan mendapatkan saran dan masukan layanan yang ada di STMIK Muhammadiyah Paguyangan.

\subsection{Alur Penelitian}

Alur pada penelitian ini disesuikan dengan kerangka kerja TOGAF ADM, sehingga nantinya akan didapatkan sebuah model arsitektur enterprise. Proses yang nantinya digunakan yaitu fase Prelimentery, fase A. Architecture Vision, fase B. Business Architecture, fase C. Information system architecture, fase d. Technology Architecture. Alur penelitian ini di sajikan seperti pada gambar 2 .

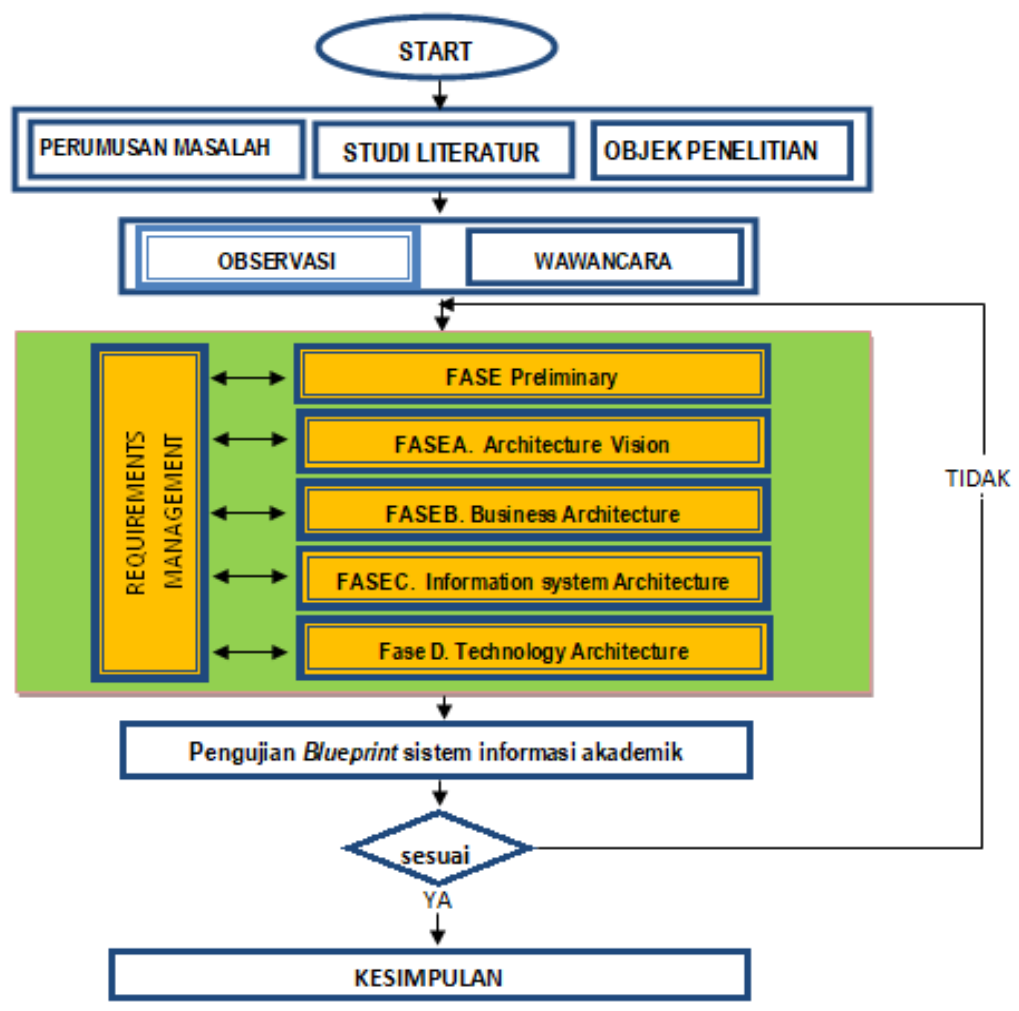

Gambar 1. Alur kerangka kerja Penetian

\section{HASIL DAN PEMBAHASAN}

\subsection{Analisis Dan Perancangan Arsitektur Sistem}

Penelitian ini diawali dengan menetapkan rumusan masalah, menetapkan tujuan penelitian dan ruang lingkup masalah, selanjutnya dilakukan studi literatur dan studi lapangan dalam hal ini STMIKMPB sebagai Objek penelitian selanjutnya dilakukan observasi dan wawancara untuk mengidentifikasi terhadap tujuan bisnis yang terdapat pada rencana strategis organisasi, mengidentifikasi proses bisnis saat ini yang ada pada sistem akademik, dan visi institusi STMIKMPB tahapan selanjutnya yaitu melakukan identifikasi Business Architecture yang telah dimiliki oleh institusi STMIKMPB untuk dijadikan acuan dalam pengembangan Business Architecture tersebut. Pada tahap perancangan arsitektur penulis menggunakan TOGAF ADM 
sebagai Baseline atau acuan dalam pengembangannya. Fase pertama dari kerangka kerja TOGAF ADM terdiri dari tiga tahapan yaitu preliminery phase, arsitecture vision, Business Architecture, ketiga tahapan yang ada pada TOGAF ADM tersebut digunakan untuk mendalami business architecure yang di miliki institusi STMIKMPB di bidang akademik. Tahapan selanjutnya yaitu information system architecture dan technology architecture.

a. Fase Preliminary

Tahapan ini mendeskripsikan inisiasi perencanaan dan persiapan dalam rangka memenuhi kriteria arah bisnis enterprise termasuk mendevinisikan prinsip-prinsip arsitektur karena prinsip arsitektur menjadi dasar dalam pengambilan keputusan terkit dengan Teknologi informasi, sehingga setiap prinsip yang dibuat akan mengacu pada keinginan membangun sebuah perancangan arsitektur teknologi informasi yang sesuai dengan institusi dan dapat membantu dalam mencapai visi misi institusi STMIKMPB.

\section{b. Fase Architecture Vision}

Perancangan arsitektur SI/TI yang baik adalah yang relevan (dapat menjawab) permasalahan-permasalahan aktual organisasi baik ditingkat strategis maupun ditingkat operasional. Pada fase ini dilakukan identifikasi requirements, requirements ini berupa misi dari institusi STMIKMPB yaitu menjadi sekolah tinggi yang mandiri, inovatif dan bertaraf internasional dalam bidang komputer, mengabdi kepada kepentingan kemanusiaan, dijiwai nilai-nilai islam berkemajuan. Untuk mewujudkan visi tersebut maka di rumuskan misi :

1) Menyelenggarakan catur darma perguruan tinggi secara profesional, inofatif dan mandiri dengan mengacu pada standar nasional maupun internasional

2) Menjadi pusat kajian dalam teknologi komputer untuk pengembangan, pendayagunaan dan pemenuhan kebutuhan pasar tenaga kerja di lingkup nasional maupun internasional.

3) Menghasilkan lulusan yang unggul, berwawasan kemandirian dan berkemampuan tinggi dalam bidang teknologi komputer dijiwai nilainilai islam berkemajuan.

4) Meningkatkan kualitas, produktivitas dan integritas lulusan dalam pembangunan nasional dengan mengedepankan nilai-nilai kemanusiaan.

5) Mengusahakan kerja sama kolaborasi dan lainnya dengan berbagai lembaga/institusi yang relevan untuk menumbuh kembangkan kreatifitas dan inovasi berkelanjutan.

\section{c. Fase Business Architecture}

Tahapan ini dilakukan untuk memahami kondisi proses bisnis STMIKMPB saat ini agar dapat dibuat usulan perbaikan dengan membuat pemodelan arsitektur bisnis, sebelum membuat pemodelan arsitektur bisnis 
perlu dilakukan analisis rantai nilai baik eksternal maupun internal dengan mengelompokkan area-area fungsional menjadi dua bagian yaitu aktifitas utama dan aktifitas pendukung. Setelah area-area fungsional dikelompokkan maka selanjutnya adalah menentukan konteks dan lingkup interprise dengan cara mengidentifikasi dan menginventarisasi area-area fungsi yang dijalankan dalam organisasi, tiap area-area fungsi dapat didekomposisikan sehingga menjadi proses-proses bisnis dalam berbagai tingkatan.

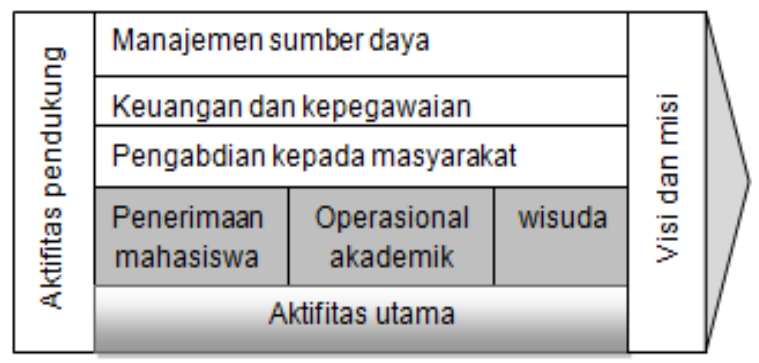

Gambar 2. Value Chain STMIKMPB

Berdasarkan hasil analisis lingkungan bisnis baik internal maupun eksternal yang sudah dilakukan selanjutnya mengevaluasi kondisi saat ini dengan analisis SWOT, yaitu dengan menjabarkan strengths (kekuatan), weakness, opportunities dan threats yang ada saat ini di STMIKMPB. Analisis SWOT digunakan untuk menggambarkan kondisi yang terjadi bukan sebagai pemecah masalah. Hasil analisis SWOT yang ada di STMIKMPB bisa dilihat pada tabel 1 .

Tabel 1. Analisis SWOT

\begin{tabular}{|l|l|}
\hline \multicolumn{2}{|c|}{ SWOT } \\
\hline \multirow{5}{*}{ Strengths (kekuatan) } & $\begin{array}{l}\text { Sebagai perguruan tinggi muhammadiyah, STMIKMPB } \\
\text { diuntungkan dengan banyaknya jaringan perguruan tinggi } \\
\text { muhammadiyah yang dapat diajak bekerja sama }\end{array}$ \\
\cline { 2 - 2 } & $\begin{array}{l}\text { Hanya ada dua kampus di brebes selatan dan STMIKMPB satu satu } \\
\text { nya kampus di wilayah brebes. }\end{array}$ \\
\cline { 2 - 2 } & $\begin{array}{l}\text { Lokasi kampus yang strategis, dekat pusat kota bumiayu dan dekat } \\
\text { dengan jalan utama. }\end{array}$ \\
\cline { 2 - 2 } & Setiap tahun jumlah mahasiswa baru selalu meningkat. \\
\cline { 2 - 2 } & $\begin{array}{l}\text { Kurang nya sumber daya pengajar yang linier dengan program studi } \\
\text { SI/TI }\end{array}$ \\
\hline Weakness (kelemahan) & Kurang nya ruangan yang digunakan untuk perkuliahan \\
\cline { 2 - 2 } & Kurang nya fasilitas praktikum untuk mahasiswa. \\
\hline Opportunities \\
(peluang) & $\begin{array}{l}\text { Minat program studi SI dan TI di kabubaten brebes sangat } \\
\text { besar.dibuktikan dengan hasil Quisioner yang di lakukan kepada } \\
\text { siswa / siswi SMA / MA / SMK di kabubaten brebes }\end{array}$ \\
\hline Threads (tantangan) & Meningkatnya kebutuhan SDM dibidang Teknologi informasi \\
\cline { 2 - 2 } & Terus Berkembangnya ilmu pengetahuan dan teknologi \\
\hline
\end{tabular}

\section{d. Fase information system architecture}

Pada fase ini dilakukan dengan membagi menjadi dua tahapan yaitu tahapan membangun arsitektur data yang membahas data serta informasi 
yang dibutuhkan untuk mendukung pengambilan keputusan disetiap unit kerja dan pertukaran data/informasi pada tiap unit kerja dan membangun pemodelan arsitektur aplikasi yang membahas tentang aplikasi yang dibutuhkan untuk pengolahan dan pendistribusian data/informasi sehingga nantinya bisa membantu dalam pengambilan keputusan pada setiap unit kerja.

1) Arsitektur data

Data yang benar dan akurat sangat dibutuhkan agar informasi yang di proses aplikasi dapat dipercaya dan bisa dipertanggung jawabkan, untuk itu perlu adanya pengelolaan data yang terpusat dan terintegrasi sehingga memudahkan dalam singkronisasi dan koordinasi data yang diharapkan dapat memberikan data yang akurat dan benar terhadap data yang disajikan. Mengidentifikasi calon kandidat class dilakukan untuk mendefinisikan arsitektur data. Hasil analisis kandidat class dapat dilihat pada tabel 2 .

Tabel 2. Kandidat Class

\begin{tabular}{|l|l|l|l|}
\hline No & Kandidat class & No & Kandidat class \\
\hline 1 & Login & 22 & Ruang_kuliah \\
\hline 2 & Panitia_PMB & 23 & kelas \\
\hline 3 & Jadwal_piket & 24 & Daftar_hadir_dosen \\
\hline 4 & Calon_mahasiswa & 25 & Mata_kuliah \\
\hline 5 & Asal sekolah & 26 & Nilai \\
\hline 6 & Pembayaran_registrasi & 27 & Perwalian \\
\hline 7 & Jadwal_tes & 28 & Jadwal_ujian \\
\hline 8 & Soal_ujian & 29 & Jadwal_lab \\
\hline 9 & Hasil_tes & 30 & Transkrip_nilai \\
\hline 10 & registrasi & 31 & Absensi_Mhs \\
\hline 11 & NIM & 32 & Kerja_praktek \\
\hline 12 & Kurikulum & 33 & Tugas_akhir \\
\hline 13 & Kalender_akademik & 34 & Cuti_akademik \\
\hline 14 & BAAK & 35 & Panitia_wisuda \\
\hline 15 & Mahasiswa & 36 & Calon_wisuda \\
\hline 16 & Dosen & 37 & Ijazah \\
\hline 17 & Dosen_pembimbing & 38 & Transkrip_akade-mik \\
\hline 18 & Dosen-wali & 39 & Mhs_Drop_Out \\
\hline 19 & Program_studi & 40 & Alumni \\
\hline
\end{tabular}

2) Arsitektur Aplikasi

Tujuan arsitektur aplikasi adalah untuk mendefinisikan jenis-jenis aplikasi utama yang dibutuhkan untuk mengolah data dan mengatur fungsi bisnis di STMIKMPB. Aplikasi yang diharapkan ada merupakan aplikasi yang tidak berubah relative dan stabil, tetapi dapat mengalami perubahan pada fitur dan kemampuan, sedangkan teknologi yang digunakan untuk menopang aplikasi tersebut akan berubah berdasarkan perkembangan dan kebutuhan teknologi. 


\section{e. Fase Technology Architecture}

Arsitektur teknologi merupakan pendefinisian kebutuhan teknologi yang perlu disediakan dilingkungan bisnis untuk menjalankan arsitektur data yang dapat mengelola data berdasarkan arsitektur aplikasi, sehingga dapat dikatakan arsitektur teknologi merupakan kebutuhan inti yang harus disediakan untuk mendukung jalanya data dan aplikasi yang digunakan oleh organisasi.

Hasil dari tahapan-tahapan yang telah dilakukan dalam pemodelan arsitekur sistem informasi akademik menggunakan kerangka kerja TOGAF ADM didapatkan portofolio aplikasi yang di sarankan atau di ajukan untuk diterapkan di STMIKMPB, portofolio aplikasi adalah menampilkan sebuah analisis dari keseluruhan aplikasi perusahaan, baik yang ada saat ini, potensial ataupun yang masih direncanakan. pada penyusunan portofolio aplikasi perujuk pada Fase information system architecture, kemudian mengkelompokan aplikasi kedalam portofolio aplikasi Mc.Farlan[11] yang disajikan pada tabel 3.

Tabel 3. Portofolio Aplikasi

\begin{tabular}{|c|l|l|l|}
\hline Kode & \multicolumn{1}{|c|}{ Strategic } & Kode & \multicolumn{1}{|c|}{ High Potential } \\
\hline 1.1 & Aplikasi penerimaan mahasiswa baru & 1.3 & Aplikasi Ujian Tes masuk \\
1.2 & Aplikasi pengelolaan dan & & \\
penjadwalan tes masuk & 2.2 & Aplikasi E-Learning \\
2.1 & Aplikasi Perencanaan Operasional & & \\
3.1 & Akademik & & \\
3.2 & Aplikasi pengelolaan Mahasiswa & & \\
\hline 2.3 & Aplikasi pengelolaan SDM & & \\
3.3 & Aplikasi resigtrasi mahasiswa & 1.5 & Aplikasi pemasaran dan promosi \\
2.3 & Evaluasi perwalian & 1.4 & Aplikasi pembayaran pendaftaran \\
2.4 & Aplikasi hasil studi & 2.6 & Aplikasi managemen tugas akhir \\
2.5 & Aplikasi pelaporan akademik & 3.4 & Aplikasi cuti akademik \\
4.0 & Aplikasi pembuatan ijazah & 4.1 & Aplikasi data alumni \\
\hline \multicolumn{3}{|c|}{ Key Operational } & \multicolumn{3}{|c|}{ Support } \\
\hline
\end{tabular}

Untuk menggambarkan arsitektur sistem bisnis yang menjadi acuan pengembangan arsitektur sistem informasi dan juga berdasarkan prinsip dan flatform teknologi, maka digunakan TOGAF fondation architecture dan SOA adapun arsitektur sistem informasi secara keseluruhan seperti pada gambar 3. Tools yang digunakan untuk pengujian blueprint arsitektur sistem informasi perizinan dalam penelitian ini menggunakan model human Organizations Technology (Hot Fit)[12]. 


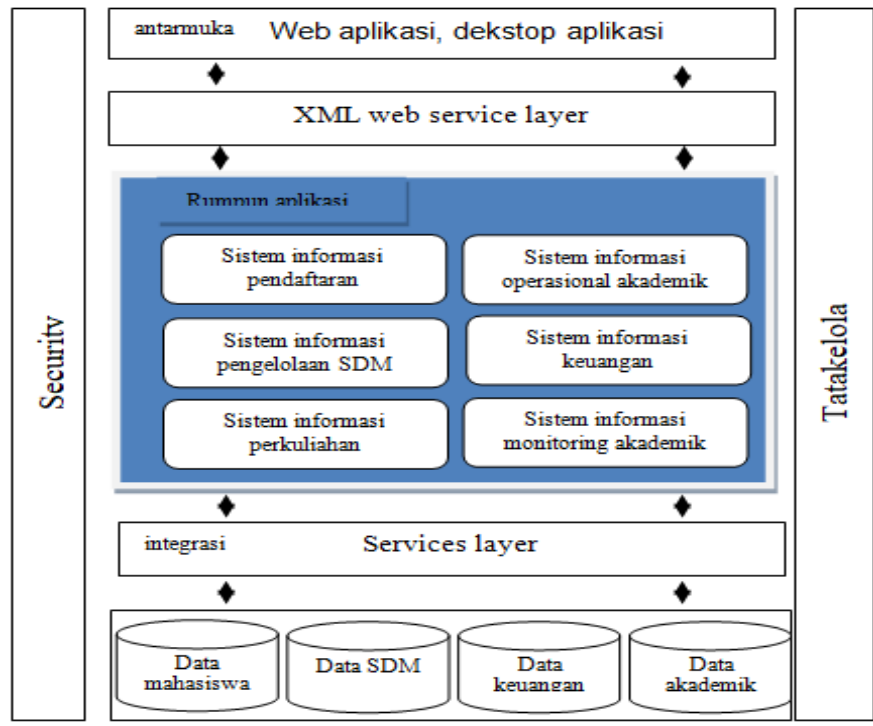

Gambar 3. SOA Arsitektur Sistem Informasi Akademik

Pada penelitian ini pengujian dilakukan pada exspert dibidang terkait. Hasil dari pengujian dari masing-masing variabel mencapai lebih dari 3,00. Sehingga didapat kesimpulan bahwa blueprint arsitektur sistem informasi akademik di STMIKMPB yang dilakukan bernilai BAIK di faktor Human, Organization, dan Technology.

\section{SIMPULAN}

Dari hasil penelitian yang telah dilakukan, diperoleh kesimpulan bahwa dengan menggunakan TOGAF ADM sebagai kerangka kerja perencanaan arsitektur enterprise sistem informasi akademik ini sudah dapat menghasilkan model arsitektur secara umum yang disesuaikan dengan visi misi di STMIKMPB. Dari Fase Business Architecture dapat diketahui bagaimana kondisi saat ini kemudian disesuaikan dengan kondisi yang diharapkan, sedangkan Berdasarkan pengelompokan menggunakan matrik Mc Farlan terdapat 4 rekomendasi sistem informasi yang berhubungan dengan akademik, perancangan model arsitektur interprise ini menghasilkan proses perbaikan kinerja proses bisnis dan sistem informasi di bagian akademik secara menyeluruh yang terintegrasi dengan bagian lain yang terkait, sehingga permasalahan-permasalahan pelayanan dan sistem informasi dapat terselesaikan, pelayanan data dan informasi yang dibutuhkan dapat diperoleh dengan cepat, tepat, dan akurat.

\section{DAFTAR PUSTAKA}

[1] Anton Yudhana, Rusydi Umar, "Implementasi Dan Pengembangan Sistem ELearning Berbasis Web Pada Stimik Muhammadiyah Paguyangan," Pros. Semin. Nas. Multi Disiplin Ilmu, No. Call For Papers Unisbank Ke-3, Pp. 104107, 2017.

[2] Endang Kurniawan, Imam Riadi, "Security Level Analysis Of Academic Information Systems Based On Standard Iso 27002: 2013 Using Sse-Cmm," Int. 
Jurnal Sains Komputer \& Informatika (J-SAKTI)

Volume 3 Nomor 1 Maret 2019, pp. 1-10

ISSN:2548-9771/EISSN:2549-7200

http://tunasbangsa.ac.id/ejurnal/index.php/jsakti

J. Comput. Sci. Inf. Secur., Vol. 16, No. 1, Pp. 139-147, 2018.

[3] Marc Lankhorst, Enterprise Architecture At Work - Enterprise Modelling, Communication And Analysis - Second Edition, Vol. 36. 2013.

[4] Kridanto Surendro, Pengembangan Rencana Induk Sistem Informasi, Informatika, Bandung. 2009.

[5] Andi Prasetyo Utomo, "Pemodelan Arsitektur Enterprise Sistem Informasi Akademik Pada Perguruan Tinggi Menggunakan Enterprise Architecture Planning," J. Simetris, Vol. 5, No. 1, Pp. 33-40, 2014.

[6] Spewak, Steven H. Enterprise Architecture Planning (Developng A Blueprint For Data, Application And Technology),. 1992.

[7] Erwin Budi Setiawan, "Pemilihan Ea Framework," Semin. Nas. Apl. Teknol. Inf., Vol. 2009, No. Snati, Pp. 114-119, 2009.

[8] Melda Agarina, "Pemanfaatan Framework Togaf Untuk Perencanaan Darmajaya Bandar Lampung ( Studi Kasus : Ibi Darmajaya Bandar Lampung )," Vol. 15, No. 2, Pp. 175-187.

[9] Imam Riadi, Rusydi Umar, Eko Handoyo, "Analisis Tata Kelola Teknologi Informasi Menggunakan Framework Cobit 5 Pada Domain Delivery, Service , And Support," Pp. 1-8, 2017.

[10] Krisdanto Surendro. Roni Yunis, "Implementasi Enterprise Architecture Perguruan Tinggi," Vol. 2010, No. Snati, Pp. 51-56, 2010.

[11] John Ward, Joe Peppard, Strategic Planning For Information System. 2002.

[12] Maryati Mohd, Jasna Kuljis, Anastasia Papazafeiropoulou, And Lampros. K. Stergioulas, "An Evaluation Framework For Health Information Systems: Human , Organization And Technology-Fit Factors ( Hot-Fit )," Vol. 7, Pp. 386398, 2007. 